\title{
Estudo da degradação de fachada de edificação litoranea: Estudo de caso em Salvador/BA
}

\author{
A. R. A. OMORE ${ }^{1 *}$, V. A. COELHO ${ }^{2}$, M. V. A. S. MENDES 3 , F. G. S. SILVA ${ }^{4}$ \\ *Autor de Contacto: abrahamrodolphe@gmail.com \\ ${ }^{1}$ PPEC, Escola Politécnica, Universidade Federal da Bahia, Salvador, Brasil \\ ${ }^{2}$ NUCCTEC, Curso Bacharelado em Engenharia Civil, Instituto Federal de Goiás, Goiânia, Brasil \\ ${ }^{3}$ Graduado em Engenharia Civil, Escola Politécnica, Universidade Federal da Bahia, Salvador, Brasil \\ ${ }^{4}$ DCE, Escola Politécnica, Universidade Federal da Bahia, Salvador, Brasil
}

\begin{abstract}
RESUMO
A eficiência da manutenção de fachadas de edifícios comuns é bastante relevante em termos de durabilidade e funcionalidade. Isso requer um método preciso para planejar as diferentes ações envolvidas. A NBR 15575 vem ajudando para uma maior orientação na execução de fachadas a partir de parâmetros que otimizam o olhar técnico sobre o uso dos sistemas de uma edificação. Nesse artigo foi realizado um levantamento e análise das principais manifestações patológicas de fachada de edificação litorânea localizada em salvador/Bahia, para isso foi realizada avaliação visual in loco, com levantamento de patologias com coleta de imagens utilizando câmera de alto zoom profissional e Drone na qual realizou-se todo o diagnóstico e mapeamento dos danos apresentados. De maneira geral a edificação, nos sistemas avaliados, apresenta riscos estruturais, com várias fissuras higrotérmicas devendo ser realizadas de forma imediata intervenções.
\end{abstract}

Palavras-chave: Fachada. Degradação. Manifestações patológicas. Vida útil.

\section{Degradation study of coastal building façade: Case study in Salvador / BA}

\begin{abstract}
The efficiency of the maintenance of façades of common buildings is very relevant in terms of durability and functionality. This requires a precise method for planning the different actions involved. NBR 15575 has been helping to provide greater guidance in the execution of façades based on parameters that optimize the technical view on the use of building systems. In this article, a survey and analysis of the main pathological manifestations of a coastal building facade located in Salvador / Bahia was carried out. For this, a visual assessment was carried out on the spot, with a survey of pathologies with image collection using a professional high-zoom camera and Drone in which all the diagnoses and mapping of the damage presented were carried out. In general, the building, in the evaluated systems, presents structural risks, with several hygrothermal fissures, and interventions must be carried out immediately.
\end{abstract}

Keywords: Facade. Degradation. Pathological manifestations. Useful life.

\section{Estudio de degradación de la fachada de un edificio costero: estudio de caso en Salvador / BA}




\section{RESUMEN}

La eficiencia del mantenimiento de fachadas de edificios comunes es muy relevante en términos de durabilidad y funcionalidad. Esto requiere un método preciso para planificar las diferentes acciones involucradas. NBR 15575 ha venido ayudando a brindar una mayor orientación en la ejecución de fachadas en base a parámetros que optimizan la visión técnica sobre el uso de los sistemas constructivos. En este artículo se realizó un relevamiento y análisis de las principales manifestaciones patológicas de la fachada de un edificio costero ubicado en Salvador / Bahía, para lo cual se realizó una valoración visual in loco, con un relevamiento de patologías con recolección de imágenes utilizando una cámara profesional de alto zoom y Drone en el que se realizaron todos los diagnósticos y mapeo de los daños presentados. En general, la edificación, en los sistemas evaluados, presenta riesgos estructurales, con varias fisuras higrotérmicas y las intervenciones deben realizarse de forma inmediata.

Palabras clave: Fachada. Degradación. Manifestaciones patológicas. Vida útil.

\section{INTRODUÇÃO}

A fachada é um elemento-chave de um edifício e influencia seu conforto, sua segurança e estética. A degradação das fachadas é um processo natural e espontâneo, e mesmo que os materiais apresentem um estado natural, estarão sujeitos às deteriorações física, química e biológica, que afetam não somente sua vida útil, mas também da edificação como um todo. $\mathrm{O}$ desempenho geral da fachada depende do desempenho de seus componentes: separação, suporte e instalações (Hermans, 1995).

Medidas de manutenção são as ações técnicas e econômicas que tentam elevar o nível de qualidade de um elemento de construção e/ou restaurar o nível de desempenho inicial. Essas ações são executadas para antecipar a falha dos elementos ou corrigir localmente os defeitos existentes, o que se denominam de manutenção proativa e reativa, respectivamente. As fachadas devem atender a requisitos e normas de maneira a evitar a ocorrência de trincas, fissuras, perdas de aderência, desplacamento cerâmico e outras manifestações patológicas. Um diagnóstico correto deve definir o problema, coletar os dados disponíveis, caracterizar as anomalias existentes e suas prováveis causas, avaliar o desempenho em serviço, verificar se as demandas dos usuários estão sendo cumpridas e, finalmente, definir as medidas corretivas, preventivas ou ações de monitoramento. Numa cidade como Salvador, que é uma das maiores concentrações urbanas do Brasil, onde se observam, durante todo ano, registros de chuva frequentemente úmida, e onde a maior parte das edificações localiza-se próxima à orla marítima, é notável a ocorrência de manifestações patológicas em diversos trechos das fachadas prediais.

Nesse contexto, diante da necessidade de conhecer mais sobre sistemas de revestimento de fachadas de edifícios, o desenvolvimento do presente trabalho apresenta estudos pioneiros relacionados às manifestações patológicas frequentes em fachadas de edificação litorânea localizada em Salvador/BA.

\section{Sistema de revestimento de fachada}

Segundo a NBR 13755, o revestimento externo é o "[...] conjunto de camadas sobrepostas e estreitamente ligadas, composto por estrutura de suporte, estrutura de alvenaria, camada de argamassa contínua e revestimento final, cuja função é proteger o edifício da chuva, umidade, meio 
atmosférico e o efeito combinado de vento e partículas. $O$ desgaste mecânico causado é forte e tem um efeito estético.

Para Silva (2006), a função básica da cobertura é arrumar a superfície e proteger a estrutura de alvenaria e concreto para melhorar a durabilidade e o desempenho geral da estrutura fechada do edifício (figura 1). Como essas funções são universais, ressalta-se que há muitas mudanças de conforme o trabalho específico.

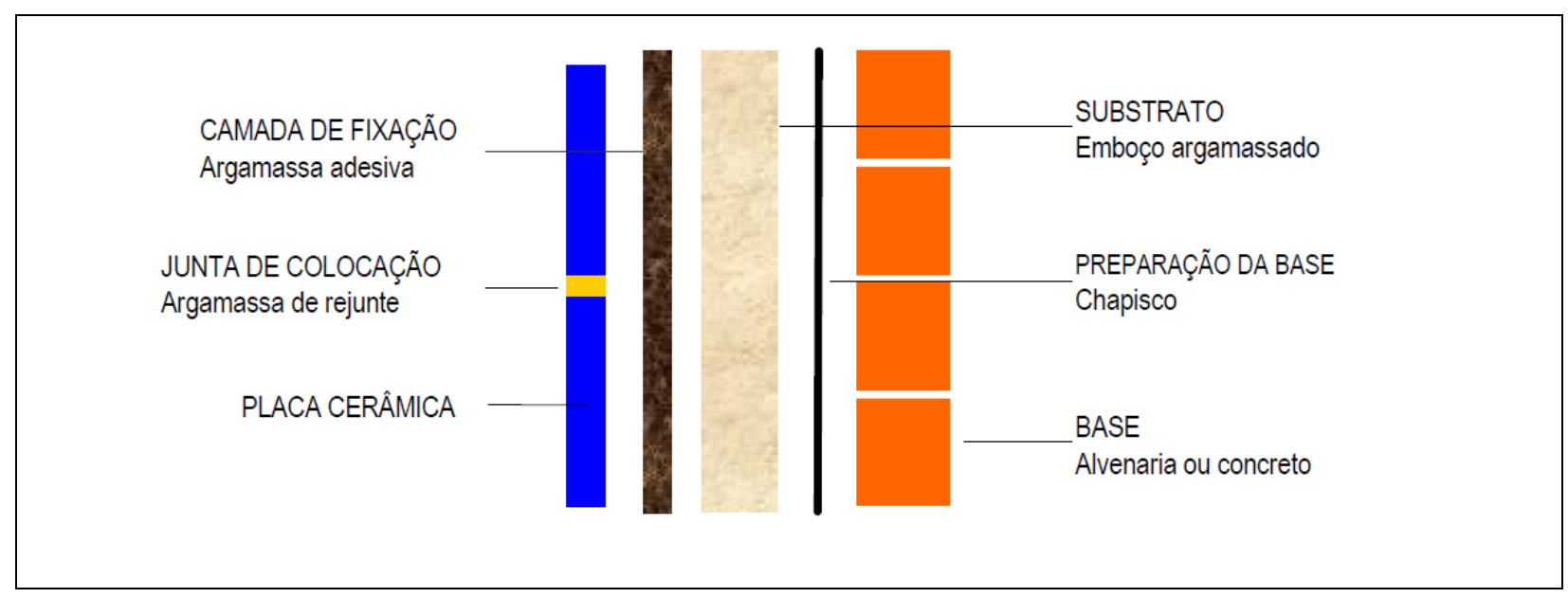

Figura 1: Camadas constituintes do revestimento cerâmico de fachada (Medeiros e Sabbatini, 1999).

O desempenho da camada de revestimento da parede cortina está relacionado à adesão entre as camadas, ao comportamento diferente dos elementos que compõem cada camada e aos diferentes efeitos de exposição ao longo do tempo. No entanto, condições de exposição e atividades de manutenção podem acelerar ou desacelerar o processo de degradação (SILVA, 2014).

\subsection{Revestimento Argamassado com Acabamento em Pintura}

Conforme a NBR 13529 (2013), os sistemas de revestimento com acabamento em pintura são definidos como um conjunto formado por revestimento em argamassa e um acabamento decorativo compatível com a natureza e as condições de exposição do substrato utilizado, atendendo, por conseguinte, ao desempenho esperado do projeto.

Para Silva (2006), o emboço tem a função de arrumar a superfície em preparação para receber outra camada de estuque ou acabamento decorativo. Também pode ser uma camada única ou estuque "São Paulo" (como geralmente é chamado em engenharia). Por outro lado, o reboco é a camada executada após o emboço, que, quando finalizada em tinta, pode aceitar camada decorativa ou constituir a decoração final.

\subsection{Revetimento Cerâmica}

A NBR 13816 (1997) define o revestimento cerâmico como uma camada fixa formada por placas de cerâmica, argamassa e argamassa. Além de proteger a fachada, o painel de cerâmica serve como parte do revestimento, transmitindo a beleza ao sistema através de sua cor e modelo. No entanto, para escolher produtos de alta qualidade, é necessário aprender mais sobre sua classificação e desempenho. 
Ainda conforme a NBR 13816 (1997), a placa cerâmica para revestimento, geralmente usada para revestir pisos e paredes, é um material composto de argila e outras matérias-primas inorgânicas formado por extrusão ou compressão, além de outros processos, e queimado a alta temperatura. Devido à grande variedade de produtos cerâmicos no mercado em termos de forma, tamanho, cor, processo de fabricação, desempenho e função, é muito importante realizar a classificação técnica e industrial.

\subsection{Substrato}

Substrato é a camada do piso ou do elemento de vedação (parede ou painel) sobre a qual a cerâmica será assentada. No caso do piso, o substrato é o contrapiso, isto é, argamassa de regularização aplicada sobre a laje de concreto, que tem a finalidade de definir caimentos e desníveis, além de homogeneizar a superfície irregular do concreto. No caso da parede de alvenaria, o substrato é o emboço (note-se que o reboco passa a ser dispensável em paredes a serem revestidas com cerâmica) (figura 2).

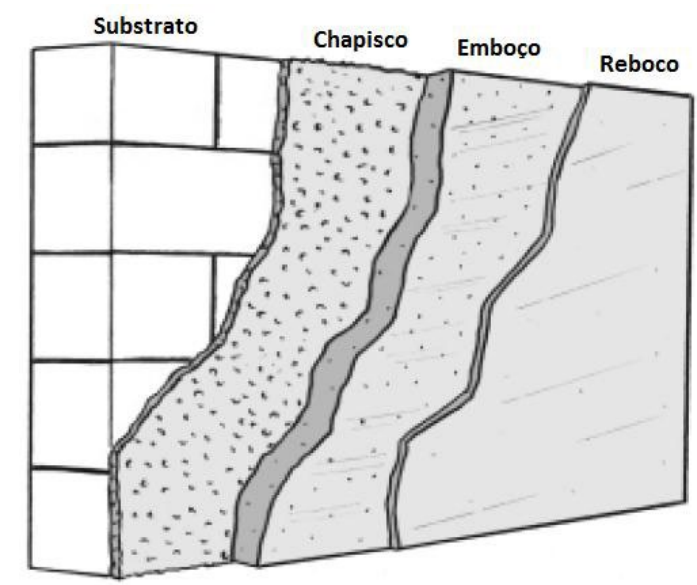

Figura 2: Sistema de revestimento em argamassa, $A B C P$ (2002).

Conforme Silva (2006), o substrato ou a camada de base é uma camada que aceita tinta de argamassa e pode ser dividida em uma camada de vedação ou uma camada estrutural de acordo com sua função na estrutura. O substrato pode ser composto de alvenaria (cerâmica, concreto, volastonita) ou até concreto.

\subsection{Chapisco}

Segundo Silva (2006), o chapisco, diferente do emboço e do reboco, não constitui uma camada de revestimento. O chapisco é definido como uma camada de preparação da base, de forma a proporcionar boa aderência da argamassa ao substrato. Ele serve para regularizar a absorção da base e melhorar a aderência. Existem diferentes tipos de chapisco: o tradicional, o industrializado e o rolado. O chapisco é uma argamassa feita de cimento e areia grossa que é aplicada na alvenaria de forma irregular. Ele é responsável por aumentar a rugosidade da superfície da alvenaria.

Segundo Leal (2003), o chapisco é um processo básico de preparação e não é considerado um revestimento. Sua espessura média é de cerca de $5 \mathrm{~mm}$, dependendo do tamanho de partícula da areia utilizada. 


\subsection{Emboço, Reboco, Camada Única}

Emboço é a camada de argamassa aplicada após o chapisco que proporciona a superfície requerida para a aplicação do acabamento final. Caso esta camada requeira espessura elevada, algo superior a 30-40 $\mathrm{mm}$, detalhes especiais de reforços precisam ser contemplados, sendo que o uso de telas metálicas é bastante comum. Segundo a NBR 13529: 2013, o reboco é camada de revestimento utilizada para cobrimento do emboço, propiciando uma superfície que permite receber o revestimento decorativo ou que se constitua no acabamento final.

\section{MANIFESTAÇÕES PATOLÓGICAS MAIS COMUNS EM FACHADA}

Como cada material usado em um edifício tem comportamentos diferentes, dependendo do local e da função de uso, há muitos fatores que podem causar a degradação do edifício e danificar sua durabilidade e sua função estrutural.

Conforme Gaspar e Brito (2005), a degradação é a perda da capacidade do material de responder às exigências frente aos agentes de deterioração, à natureza do material e também à própria maturação.

De acordo com John e Sato (2006), os fatores de degradação são agentes que atuam nos materiais de construção e causam grandes alterações nos materiais, resultando em desempenho reduzido. Esses agentes podem ser térmicos, mecânicos, eletromagnéticos, químicos e biológicos.

Diversas são as causas que levam à degradação da fachada externa, que geralmente é provocada por uma soma de fatores. Nesse sentido, um exemplo típico da ação combinada de degradantes é o efeito da chuva e do vento na parede externa, resultando em alterações físicas e químicas no material e promovendo, assim, a degradação do material. A ação do mecanismo de degradação é suficiente para causar rachaduras, fungos e mofo (figura 3).

\begin{tabular}{l|l}
\hline Natureza & Classe \\
\hline Agentes mecânicos & Gravidade \\
& Esforços e deformações impostas ou restritas \\
& Energia cinética \\
& Vibrações e ruídos \\
& Atritos \\
\hline Agentes eletromagnéticos & Radiação \\
& Eletricidade \\
& Magnetismo \\
\hline Agentes térmicos & Niveis extremos ou variações muito rápidas de \\
& temperatura \\
\hline Agentes químicos & Água e solventes \\
& Agentes oxidantes \\
& Agentes redutores \\
& Ácidos \\
& Bases \\
& Sais \\
& Quimicamente neutros \\
\hline Agentes biológicos & Vegetais e microrganismos \\
& Animais \\
\hline
\end{tabular}

Figura 3: - Natureza dos agentes de degradação, ASTM 632:1996 ISO 15686-2, 2001.

\subsection{Manchas na Pintura - Bolor ou Mofo}


As manchas constituem a anomalia estética mais comum em fachadas e podem ocorrer em fachadas pintadas e cerâmicas. As manchas podem ser divididas em: manchas com sinais de umedecimento, manchas biológicas, intemperismo e geradores de manchas.

Para Segat (2005), a água absorvida e a temperatura do edifício são fatores que determinam a aparência e a extensão do bolor no revestimento. Nesse sentido, a umidade condensada, a ventilação insuficiente e a permeabilidade do revestimento à umidade externa são fatores que causam a umidade, o que é propício ao acúmulo de bolor na superfície.

\subsection{Descascamento de Pintura}

Para Alves (2010), a presença de água pode causar bolhas, mofo e baixa adesão da tinta. A porosidade excessiva, por outro lado, pode causar alterações no brilho e na cor. Descascamentos e empolamentos, por sua vez, podem ocorrer devido à presença de sais minerais, no entanto a grande maioria das patologias relacionadas à pintura decorrem da preparação incorreta da superfície e de pessoal não qualificado.

\subsection{Fissuras e Trincas}

Segundo Junginger (2007), as trincas e rachaduras sempre se referem ao mesmo problema: descontinuidades mecânicas devido à concentração de esforços. Costuma-se identificar como fissuras o problema com abertura de até $0,5 \mathrm{~mm}$; trincas, até $2-3 \mathrm{~mm}$; e rachaduras, as aberturas maiores que 2-3 mm. Essa classificação, muito mais do que uma divisão teórica, é importante porque as técnicas de correção dos problemas têm de ser diferenciadas para cada caso.

As trincas, fissuras e gretagem do sistema de revestimento cerâmico são manifestações patológicas que podem causar outras patologias. Por exemplo, as trincas podem abrir espaços para a penetração de água e o aparecimento de bolhas, enfraquecendo, assim, as camadas do sistema e a separação de placas de cerâmica (LUZ, 2004).

\subsection{Eflorescências}

Segundo Franco (2008), eflorescência é um fenômeno causado pela movimentação da água nos vazios e canais localizados no interior da argamassa. A água sobe nesses vazios por ação capilar e/ou pressão, transportando, assim, sais solúveis presentes no substrato, cuja vazão está diretamente relacionada à absorção e à permeabilidade da argamassa. Esse fenômeno é entendido como a formação de depósitos cristalinos (sal) na superfície do painel devido a efeitos ambientais ou físicoquímicos. Essa patologia não afeta apenas a aparência da fachada, mas também afeta a adesão da cobertura, e constitui o impacto de problemas mais sério (como a presença de umidade) de uma construção

\subsection{Descolamento}

Segundo Medeiros (1999), as situações mais comuns de descolamento costumam ocorrer por volta de cinco anos após a conclusão da obra. Para o autor, essa situação acontece quando a ocorrência cíclica das solicitações, somada às perdas naturais de aderência dos materiais de fixação em situações de subdimensionamento do sistema, caracteriza as falhas que costumam resultar em problemas de quedas.

\subsection{Desplacamento}


Conforme Antunes (2010), o desplacamento (Figura 13) é caracterizado por uma queda de placas de cerâmica que ocorre após a separação, podendo ser uma queda de placas isoladas ou com argamassa ou gesso. Tais falhas representam um risco para a segurança dos usuários do edifício e devem ser diagnosticadas o mais rápido possível. Em geral, toda a parede externa precisa ser removida, o que é caro e trabalhoso.

\subsection{Falhas em Juntas}

As juntas são muito importantes para o desempenho correto do revestimento, pois se elas falharem, o desempenho do sistema será comprometido. As juntas são responsáveis por promover a estanqueidade do revestimento e a capacidade de absorver a deformação (SOUSA, 2008).

Segundo Antunes (2000), o envelhecimento manifesta-se nas resinas de origem orgânica pela alteração da cor e pode resultar em outros fatores que implicam fissuração e posterior queda do rejunte da fachada.

\subsection{Falhas de rejunte}

A porosidade do revestimento de granito e do material de rejuntamento, bem como as trincas e falhas de rejuntamento, estão relacionadas à quantidade de água de infiltração. Assim sendo, todas as metodologias de revestimento de acabamento de fachadas de edifícios, quer seja o mais simples revestimento de argamassa, quer seja o executado com cerâmica, ou o revestimento de placas de rocha, devem ter como preocupação a execução de procedimentos que venham a aliviar as tensões possíveis de ocorrer.

Para evitar essas patologias, é essencial promover o preenchimento completo das juntas, impedir a entrada de água e usar rejuntes compatíveis com o uso e com propriedades como elasticidade ou durabilidade (COSTA, 2011).

\subsection{Detoriaração de Placas Cerâmicas - Gretamento.}

Conforme explanam Campante e Baía (2003), o gretamento constitui uma série de aberturas inferiores a $1 \mathrm{~mm}$ que ocorrem na superfície esmaltada das placas, conferindo à superfície uma aparência de teia de aranha. Esse tipo de patologia é decorrente da perda de integridade da superfície da placa cerâmica, que pode ficar limitada a um defeito estético (no caso de gretamento), ou pode evoluir para um destacamento (no caso de trincas).

\section{ESTUDO DE CASO}

O condomínio foi construído há aproximadamente 35 anos em estrutura convencional de concreto armado, possuindo dois blocos, um nível de garagem e playground. As fachadas são constituídas de cerâmica e pintura. Está situado em região próxima ao mar, em área com classe de agressividade ambiental tipo IV - muito forte (NBR 6118), devido à proximidade do mar e o recebimento de spray salino e chuva dirigida sem barreira.

\subsection{Metodología}

Foi realizada orientação e acompanhamento do serviço de alpinismo, obedecendo aos critérios normativos na NR 18 e NR 35, na qual se realizou teste percussivo nas fachadas e marcações com tinta acrílica base d'água, obedecendo a seguinte legenda: 1 - som cavo, 2- fissuras e x - 
desplacamento. Por questões de segurança, as partes soltas da fachada foram removidas pelo alpinista.

Após isso foi realizada avaliação visual in loco, com levantamento de patologias com coleta de imagens utilizando câmera de alto zoom profissional (marca Sony - DSC H400) e Drone (marca Mavic Pro da DJI) na qual realizou-se todo o diagnóstico e mapeamento dos danos apresentado, além da realização de testes de pHmetria com solução alcoólica de Fenolftaleína para verificação de infiltrações e carbonatação.

\subsection{Localização e inspeção das manisfestações patológicas.}

- Na fachada noroeste do Bloco A e B foi realizada inspeção com descida de alpinista, marcando-se as regiões de som cavo. Além disso, registrou-se trecho de desplacamento cerâmico (Figura 4 á 7). 


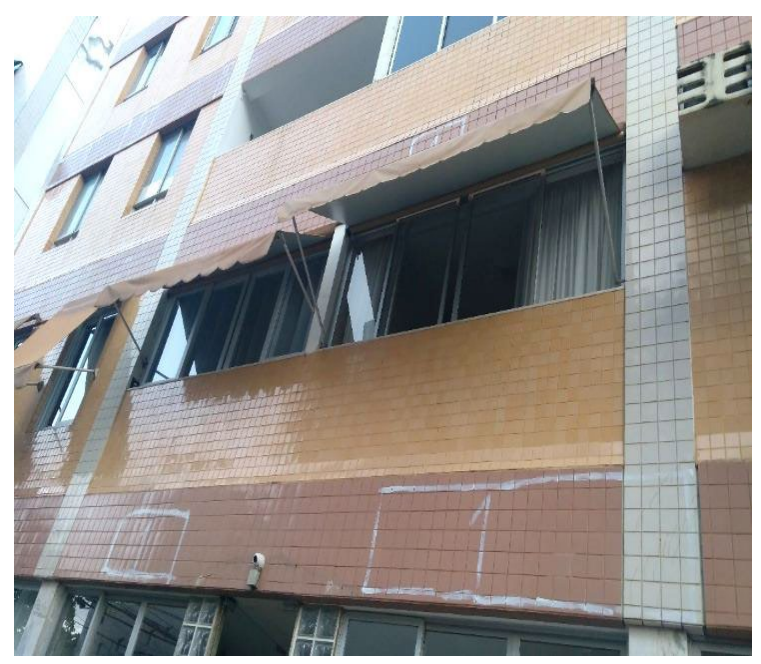

Figura 4:Marcações de som cavo na fachada noroeste do Bloco A.

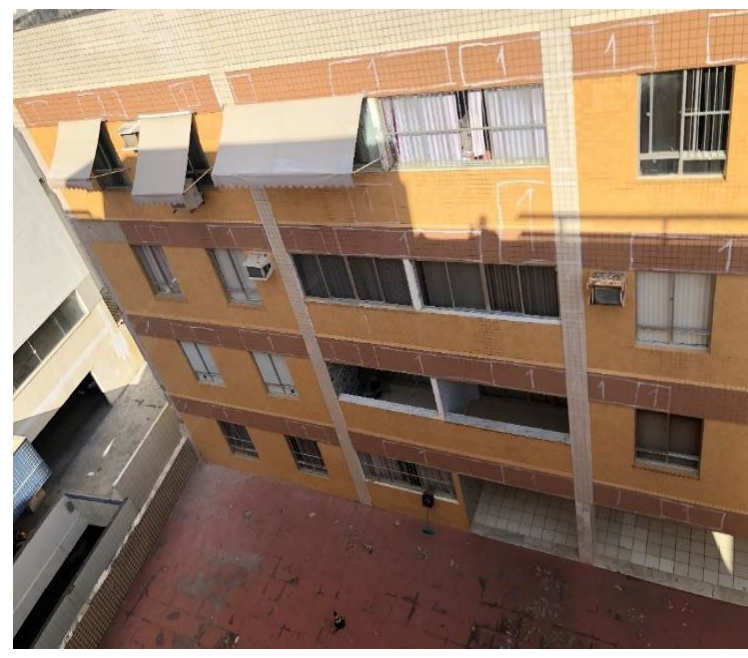

Figura 6:Marcações de som cavo e corrosão na fachada noroeste do Bloco $B$.

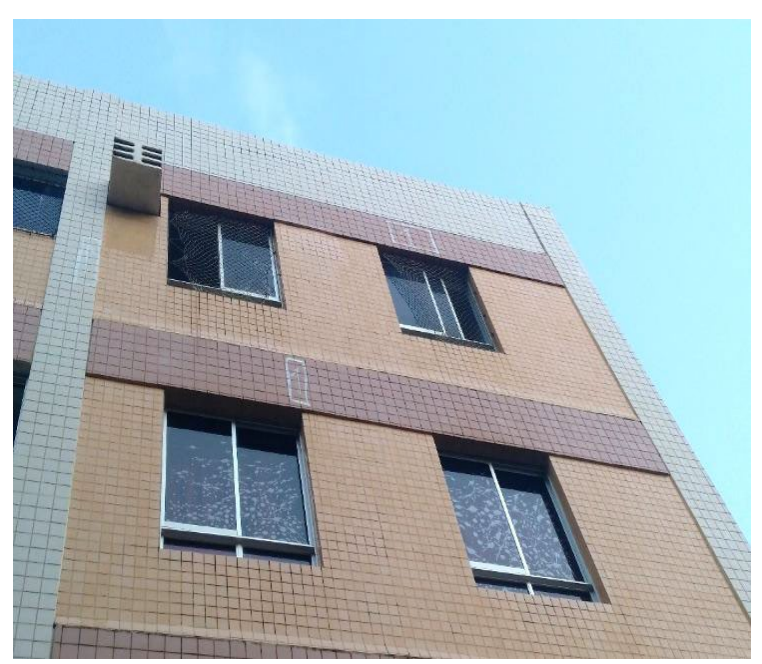

Figura 5:Marcações de som cavo na fachada noroeste do Bloco A.

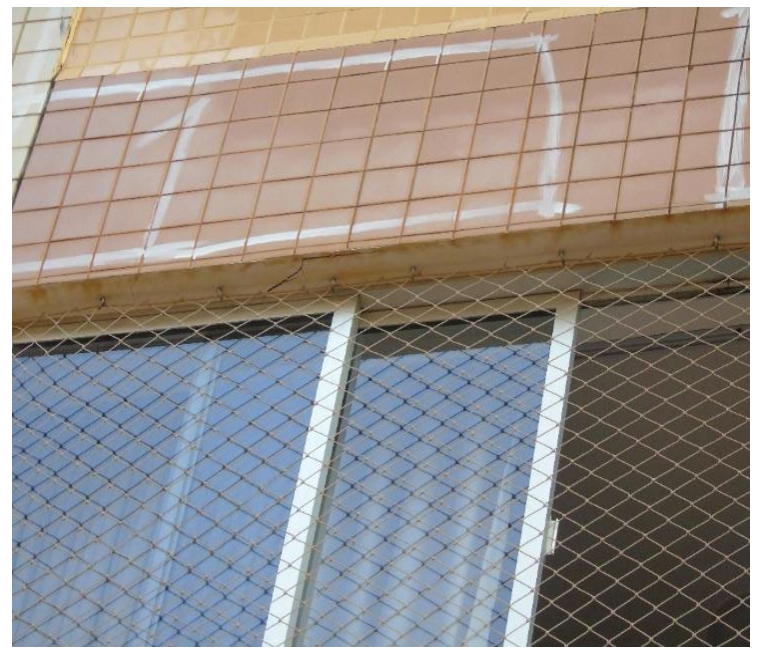

Figura 7:Corrosão em verga na fachada noroeste do Bloco B.

- Na fachada sudeste do Bloco A e B foi realizada inspeção com descida de alpinista, marcando-se as regiões de som cavo (figura 8 á 11). 

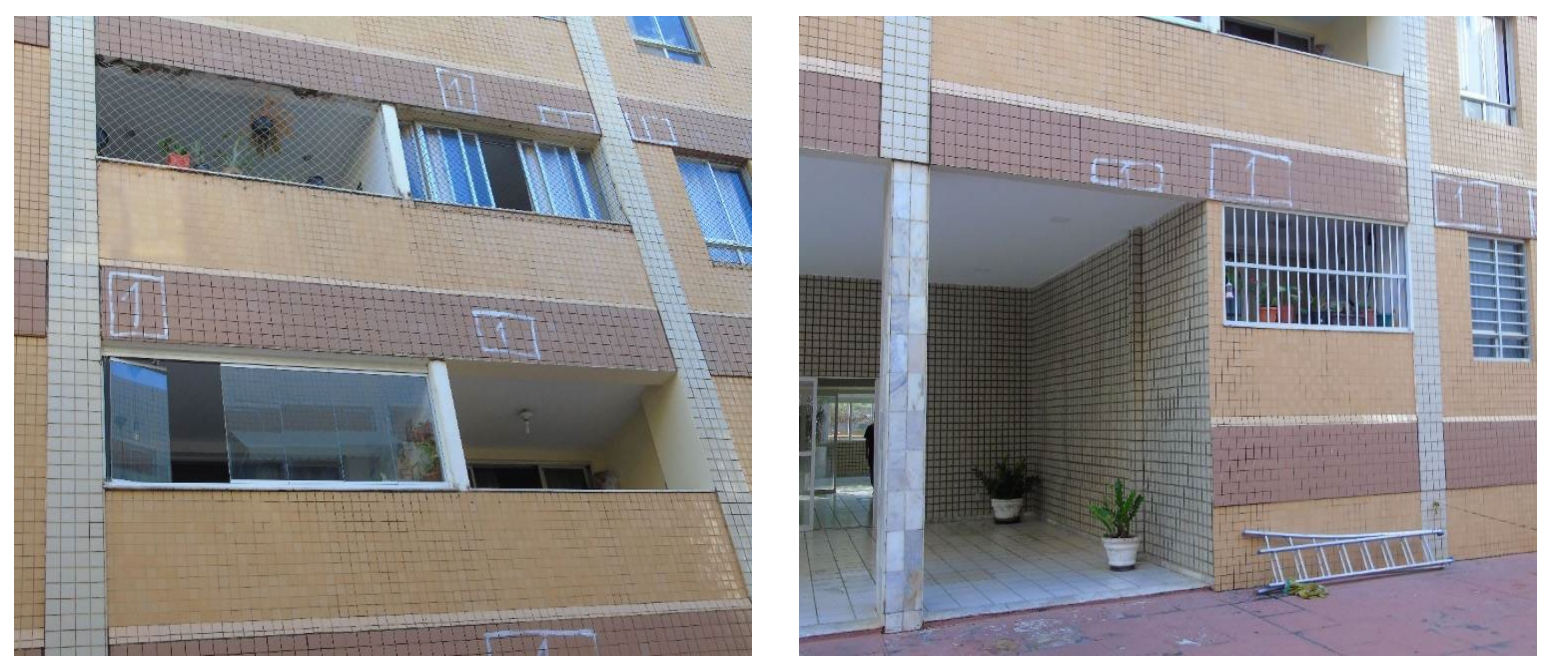

Figura 8: Marcações de som cavo na fachada sudeste do Bloco A.

Figura 9:Marcações de som cavo na fachada sudeste do Bloco A.

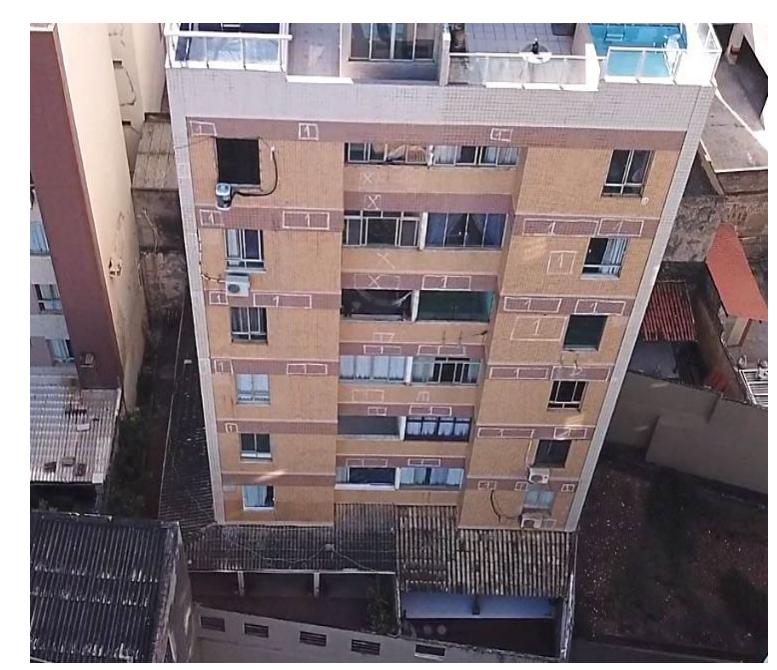

Figura 10: Vista da fachada sudeste do Bloco $B$ com marcações de som cavo e revestimento solto.

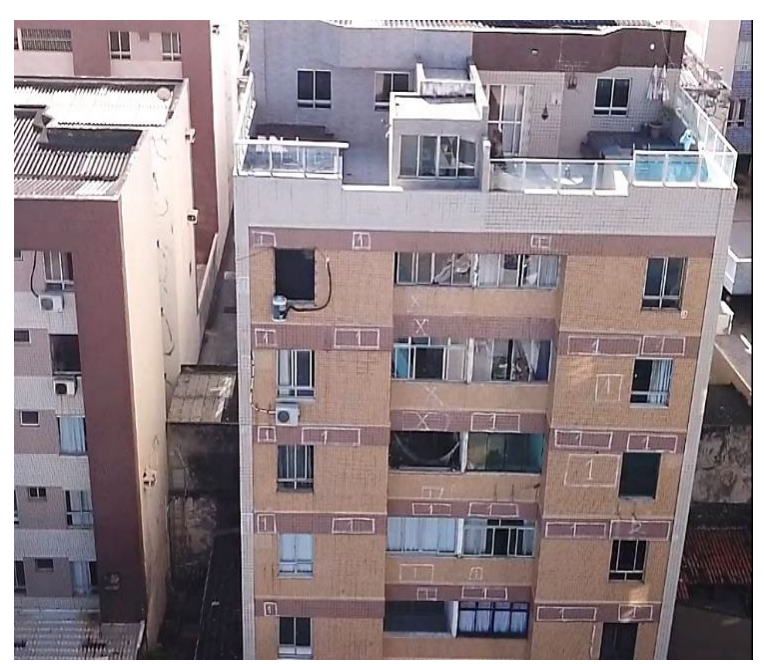

Figura 11: Vista da fachada sudeste do Bloco $B$ com marcações de som cavo e revestimento solto.

- Na fachada nordeste do Bloco A foram registradas fisuras mapeadas de origem higrotérmicas (figura 12 a 15). 

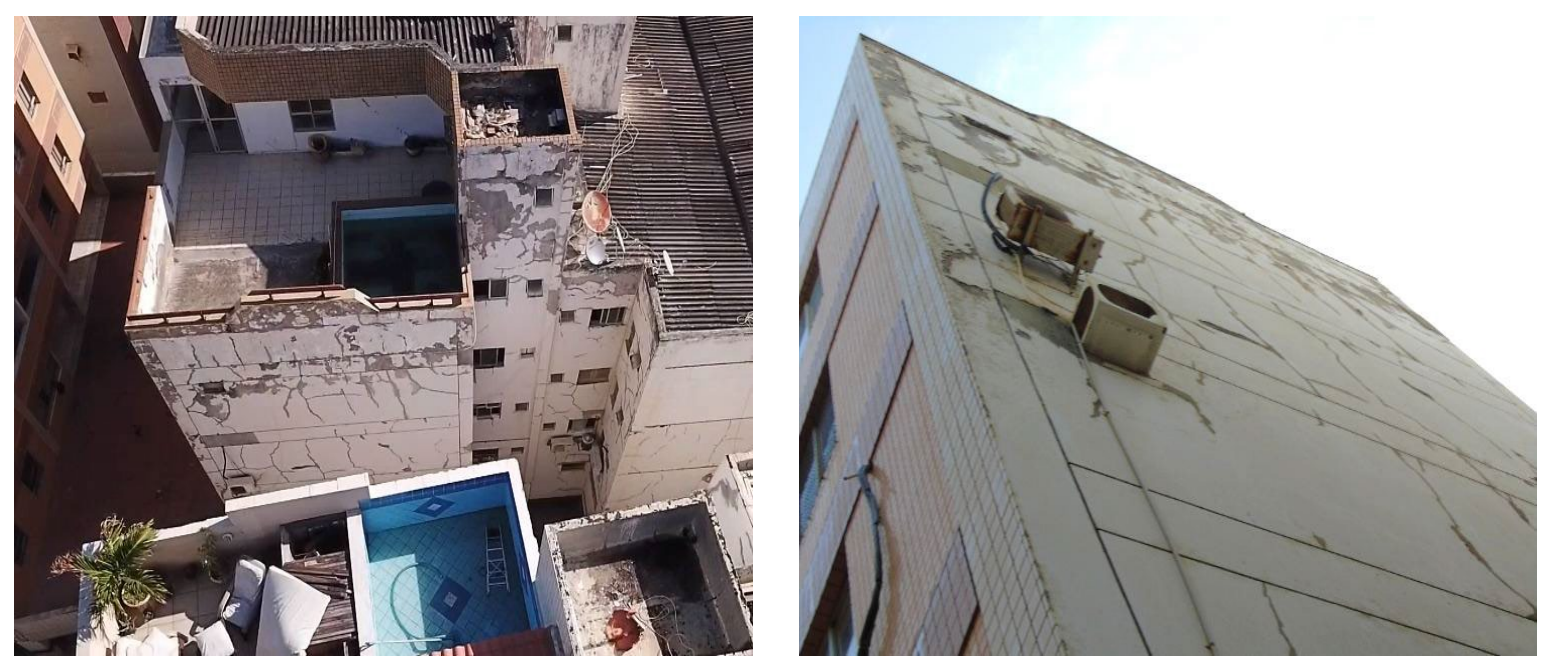

Figura 12:Vista da fachada nordeste do Bloco A.

Figura 13:Fissuras na fachada nordeste do Bloco A.
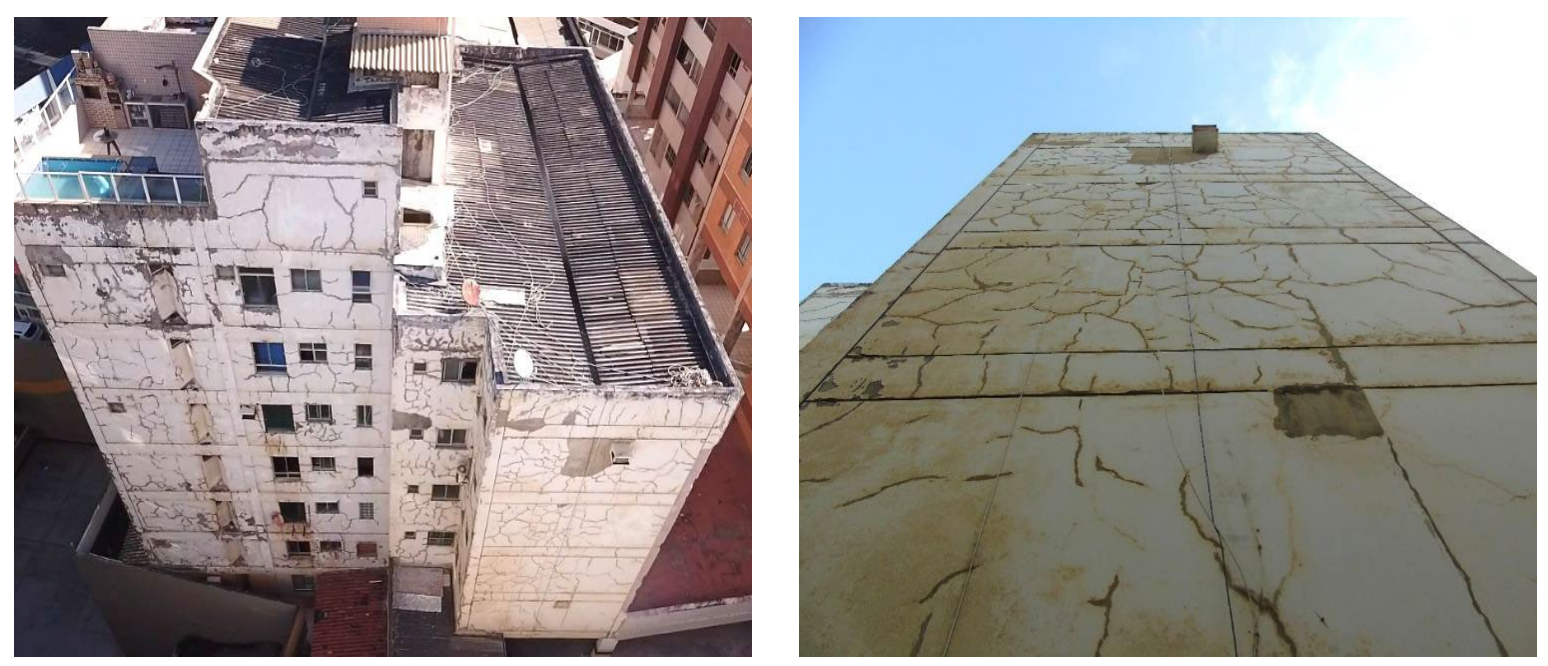

Figura 14:Vista da fachada nordeste do Figura 15:Fissuras na fachada nordeste do Bloco $B$ com fissuras, corrosão e Bloco B. desplacamento.

- Na fachada sudoeste do Bloco A e B foram registradas fisuras mapeadas de origem higrotérmicas (figura 16 a 19). 

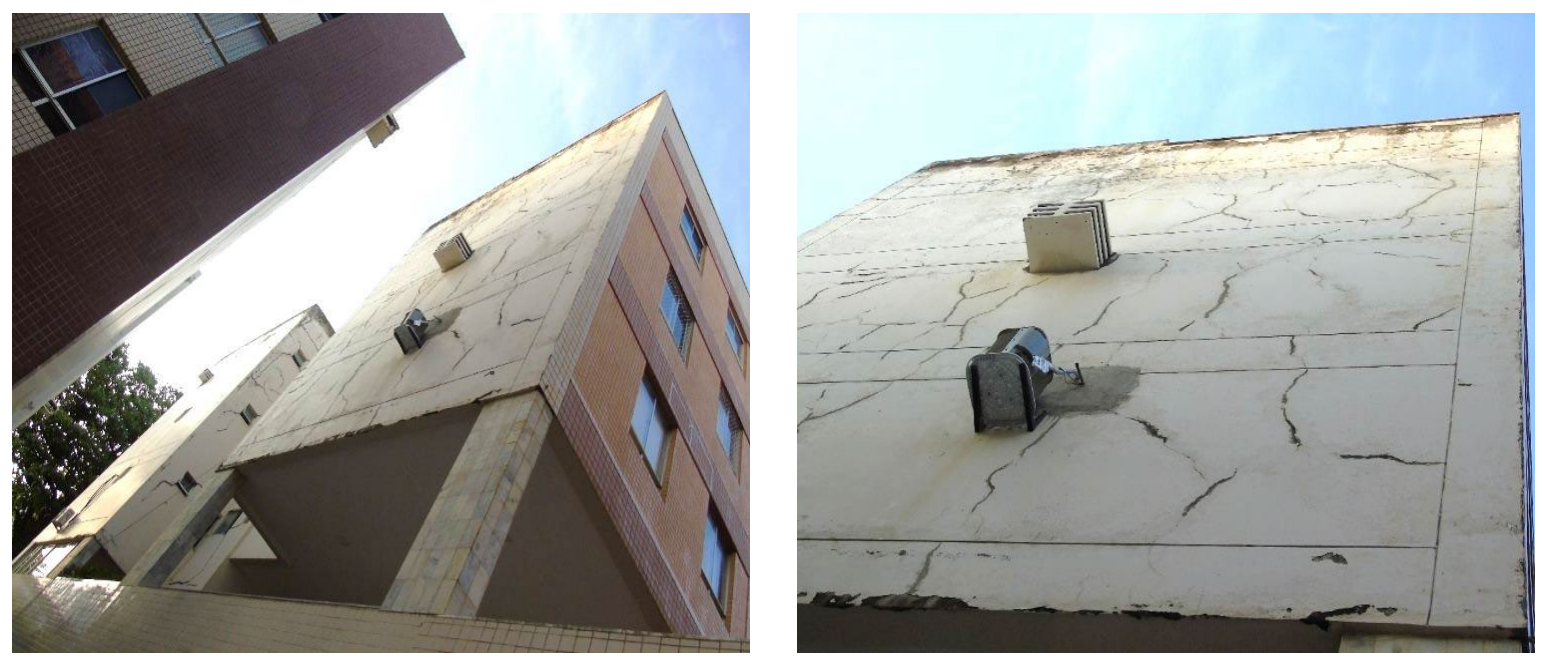

Figura 16:Vista da fachada sudoeste do Bloco A.

Figura 17:Fissuras na fachada sudoeste do Bloco A.
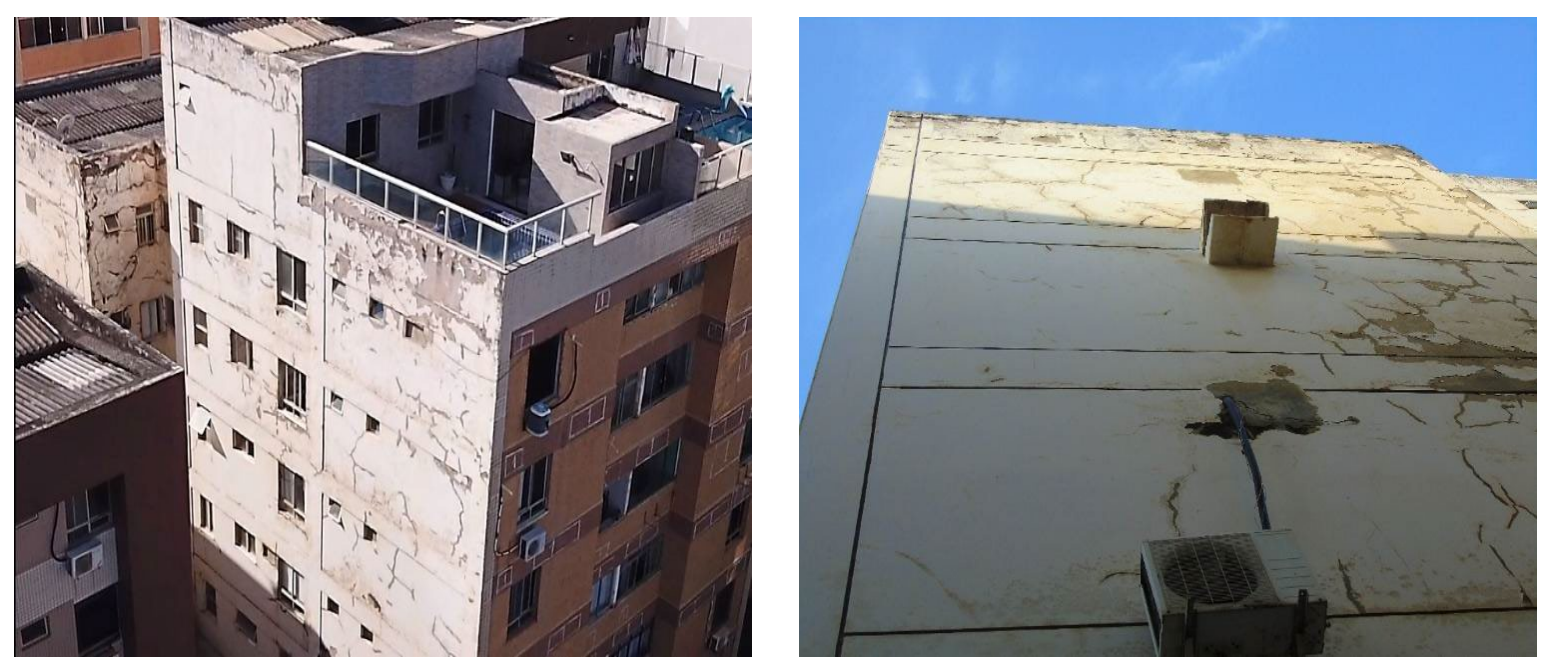

Figura 18:Vista da fachada sudoeste do Figura 19:Fissuras na fachada sudoeste do Bloco B com fissuras e desplacamento. Bloco $B$.

\section{Resultados}

Os quantitativos de danos estão apresentados na Tabela 1 a Tabela 4. 
Tabela 1: Área das Fachadas

\begin{tabular}{|c|c|c|c|c|c|c|}
\hline \multicolumn{7}{|c|}{ QUANTITATIVO DE REVESTIMENTO DAS FACHADAS - BLOCO A } \\
\hline Revestimento & Unidade & $\begin{array}{l}\text { Fachada } \\
\text { Noroeste }\end{array}$ & $\begin{array}{l}\text { Fachada } \\
\text { Sudeste }\end{array}$ & $\begin{array}{l}\text { Fachada } \\
\text { Sudoeste }\end{array}$ & $\begin{array}{l}\text { Fachada } \\
\text { Nordeste }\end{array}$ & TOTAL \\
\hline Pastilha Branca & $\mathrm{m}^{2}$ & 66,59 & 47,58 & - & - & 114,17 \\
\hline Pastilha Amarela & $m^{2}$ & 78,47 & 98,98 & - & - & 177,45 \\
\hline Pastilha Marrom & $m^{2}$ & 52,36 & 59,46 & - & - & 111,82 \\
\hline Pintura & $m^{2}$ & - & - & 258,91 & 330,38 & 589,29 \\
\hline Total & $m^{2}$ & 197,42 & 206,02 & 258,91 & 330,38 & 992,73 \\
\hline
\end{tabular}

\begin{tabular}{|c|c|c|c|c|c|c|}
\hline \multicolumn{7}{|c|}{ QUANTITATIVO DE REVESTIMENTO DAS FACHADAS - BLOCO B } \\
\hline Revestimento & Unidade & $\begin{array}{l}\text { Fachada } \\
\text { Noroeste }\end{array}$ & $\begin{array}{l}\text { Fachada } \\
\text { Sudeste }\end{array}$ & $\begin{array}{l}\text { Fachada } \\
\text { Sudoeste }\end{array}$ & $\begin{array}{l}\text { Fachada } \\
\text { Nordeste }\end{array}$ & TOTAL \\
\hline Pastilha Branca & $m^{2}$ & 41,26 & 32,10 & - & - & 73,36 \\
\hline Pastilha Amarela & $m^{2}$ & 92,41 & 126,08 & - & - & 218,49 \\
\hline Pastilha Marrom & $\mathrm{m}^{2}$ & 52,36 & 61,11 & - & - & 113,47 \\
\hline Pintura & $\mathrm{m}^{2}$ & - & - & 360,98 & 391,36 & 752,34 \\
\hline Total & $\mathrm{m}^{2}$ & 186,03 & 219,29 & 360,98 & 391,36 & 1157,66 \\
\hline
\end{tabular}

Tabela 2: Quantitativo de danos da fachada

\begin{tabular}{|l|c|c|c|c|c|c|c|}
\hline \multicolumn{7}{|c|}{ QUANTITATIVO DE DANOS EM FACHADAS - BLOCO A } \\
\hline Ocorrência & Unidade & $\begin{array}{c}\text { Fachada } \\
\text { Noroeste }\end{array}$ & $\begin{array}{c}\text { Fachada } \\
\text { Sudeste }\end{array}$ & $\begin{array}{c}\text { Fachada } \\
\text { Sudoeste }\end{array}$ & $\begin{array}{c}\text { Fachada } \\
\text { Nordeste }\end{array}$ & Total & $\begin{array}{c}\text { Total } \\
\text { acrescido de } \\
\mathbf{1 0 \%}\end{array}$ \\
\hline Som Cavo & $\mathrm{m}^{2}$ & 8,98 & 10,53 & - & - & $\mathbf{1 9 , 5 1}$ & $\mathbf{2 1 , 4 6}$ \\
\hline Revestimento Solto & $\mathrm{m}^{2}$ & - & - & - & - & - & - \\
\hline Desplacamento Cerâmico & $\mathrm{m}^{\mathbf{2}}$ & 0,26 & - & - & - & $\mathbf{0 , 2 6}$ & $\mathbf{0 , 2 9}$ \\
\hline Fissura & $\mathrm{m}$ & - & - & 183,89 & 188,24 & $\mathbf{3 7 2 , 1 3}$ & $\mathbf{4 0 9 , 3 4}$ \\
\hline
\end{tabular}

\begin{tabular}{|l|c|c|c|c|c|c|c|}
\hline \multicolumn{7}{|c|}{ QUANTITATIVO DE DANOS EM FACHADAS - BLOCO B } \\
\hline Ocorrência & Unidade & $\begin{array}{c}\text { Fachada } \\
\text { Noroeste }\end{array}$ & $\begin{array}{c}\text { Fachada } \\
\text { Sudeste }\end{array}$ & $\begin{array}{c}\text { Fachada } \\
\text { Sudoeste }\end{array}$ & $\begin{array}{c}\text { Fachada } \\
\text { Nordeste }\end{array}$ & Total & $\begin{array}{c}\text { Total } \\
\text { acrescido de } \\
\mathbf{1 0 \%}\end{array}$ \\
\hline Som Cavo & $\mathrm{m}^{2}$ & 48,04 & 31,26 & - & - & $\mathbf{7 9 , 3 0}$ & $\mathbf{8 7 , 2 3}$ \\
\hline Revestimento Solto & $\mathrm{m}^{2}$ & 0,97 & 2,86 & - & - & $\mathbf{3 , 8 3}$ & $\mathbf{4 , 2 1}$ \\
\hline Fissura & $\mathrm{m}$ & - & - & 146,83 & 377,09 & $\mathbf{5 2 3 , 9 2}$ & $\mathbf{5 7 6 , 3 1}$ \\
\hline Desplacamento Cerâmico & $\mathrm{m}^{2}$ & 5,32 & - & - & - & $\mathbf{5 , 3 2}$ & $\mathbf{5 , 8 5}$ \\
\hline
\end{tabular}


Tabela 3: Quantitativo de corrosão bloco B

\begin{tabular}{|c|c|c|c|}
\hline \multicolumn{2}{|c|}{ QUANTITATIVO DE CORROSÃO TORRE B } \\
\hline Fachada & Unidade & Total & $\begin{array}{c}\text { Total } \\
\text { acrescido de } \\
\mathbf{3 0 \%}\end{array}$ \\
\hline Fachada Noroeste & $\mathrm{m}^{2}$ & 8,07 & 10,49 \\
\hline Fachada Sudeste & $\mathrm{m}^{2}$ & 0 & 0 \\
\hline Fachada Sudoeste & $\mathrm{m}^{2}$ & 0 & 0 \\
\hline Fachada Nordeste & $\mathrm{m}^{2}$ & 7,16 & 9,31 \\
\hline Área de Ventilação & $\mathrm{m}^{2}$ & 2,1 & 2,73 \\
\hline Total & $\mathrm{m}^{\mathbf{2}}$ & $\mathbf{1 7 , 3 3}$ & $\mathbf{2 2 , 5 3}$ \\
\hline
\end{tabular}

Tabela 4: Quantitativo total por cor de pastilha

\begin{tabular}{|c|c|c|c|c|}
\hline \multicolumn{5}{|c|}{ QUANTITATIVO POR COR DE PASTILHA } \\
\hline Ocorrência & Unidade & $\begin{array}{c}\text { Pastilha } \\
\text { Branca }\end{array}$ & $\begin{array}{c}\text { Pastilha } \\
\text { Amarela }\end{array}$ & $\begin{array}{c}\text { Pastilha } \\
\text { Marrom }\end{array}$ \\
\hline Som Cavo & $\mathrm{m}^{\mathbf{2}}$ & 8,61 & 9,96 & 83,08 \\
\hline $\begin{array}{c}\text { Revestimento Solto e } \\
\text { Desplacamento }\end{array}$ & $\mathrm{m}^{2}$ & 4,84 & 1,20 & 3,76 \\
\hline Total & $\mathrm{m}^{\mathbf{2}}$ & $\mathbf{1 3 , 4 5}$ & $\mathbf{1 1 , 1 6}$ & $\mathbf{8 6 , 8 4}$ \\
\hline Total acrescido de 10\% & $\mathrm{m}^{\mathbf{2}}$ & $\mathbf{1 4 , 8 0}$ & $\mathbf{1 2 , 2 8}$ & $\mathbf{9 5 , 5 2}$ \\
\hline
\end{tabular}

\section{CONCLUSÃO}

Nas fachadas com revestimento cerâmico, através da descida do alpinista e realização dos testes de percussão detectou-se vários trechos de som cavo, principalmente nas pastilhas marrons. As fachadas em pintura encontram-se fissuradas e com algumas regiões de corrosão, com principal ocorrência na fachada nordeste do Bloco B. Recomenda-se a troca do sistema de revestimento cerâmico e a impermeabilização da área após a remoção, bem como a imediata recuperação estrutural dos elementos estruturais. De maneira geral a edificação, nos sistemas avaliados, apresenta riscos estruturais, devendo ser realizadas de forma imediata intervenções para a recuperação estrutural dos elementos com corrosão.

\section{REFERENCIAS}

\section{Normas:}

Associação Brasileira de Normas Técnicas. (2012). NBR 5674: manutenção de edificações: procedimento. Rio de Janeiro.

Associação Brasileira de Normas Técnicas. (2014). NBR 6118: projetos de estruturas de concreto: procedimento. Rio de Janeiro. 
SILVA, T. J (1998), Predicción de la vida útil de forjados unidireccionales de hormigón mediante modelos matemáticos de deterioro. 1998. 290f. Tese (Doutorado em Engenharia Civil)

Patologia das argamassas de revestimento: análise e recomendações. (1988) In: SIMPÓSIO DE DESEMPENHO DE MATERIAIS E COMPONENTES DE CONSTRUÇÃO CIVIL, 1., 1988, Florianópolis. Anais [...]. Florianópolis: UFSC p. 157-170.

SOUZA, V.; RIPPER, T (2009), Patologia, recuperação e reforço de estruturas de concreto. São Paulo: PINI.

VIEIRA, G. L (2003), Estudo do processo de corrosão sob a ação de íons cloreto em concretos obtidos a partir de agregados reciclados de resíduos de construção e demolição. Porto Alegre: PPGEC/UFRGS, 150p. 